\title{
PROFESSORA, ENGENHEIRA E MULHER: O SUJEITO DA EXPERIÊNCIA NO PROCESSO AUTOFORMATIVO DE PROFESSORES
}

\section{INALDA TEREZA SALES DE LIMA}

https://orcid.org/0000-0001-6125-4133

Instituto Federal de Educação, Ciência e Tecnologia do Amazonas

\section{NILTON PAULO PONCIANO}

https://orcid.org/0000-0002-6033-2563

Instituto Federal de Educação, Ciência e Tecnologia do Amazonas

RESUMO Este artigo apresenta a narrativa (auto)biográfica de uma professora do Instituto Federal de Educação, Ciência e Tecnologia do Amazonas (IFAM), e acadêmica do Mestrado Profissional em Ensino Tecnológico (MPET), com o objetivo de problematizar as dimensões formativas da autora na mediação entre a estudante dos anos 1970 e a professora de Desenho Técnico. A ideia da pesquisa surge de uma fotografia do Museu Moacir Andrade e Sala Memória, em que a pesquisadora/ professora aparece em um desfile cívico, como estudante. Baseada na pesquisa narrativa como metodologia, conclui-se que o método (auto)biográfico como procedimento de análise possibilita a autoformação pela análise de narrativas biográficas.

Palavras-chave: Pesquisa narrativa. (Auto)biografia. Formação de professores.

\section{ABSTRACT PROFESSOR, ENGINEER AND WOMAN: THE SUBJECT OF EXPERIENCE IN THE TEACHERS' SELF-FORMING PROCESS}

This article presents an autobiographical narrative of a master 's teacher of the Master' $s$ Degree in Professional Education - MPET, which analyzes the female presence at the Federal Technical School of Amazonas - ETFA in the context of the 1970s, the decade in which women were accepted in that school. The report is made from a photograph of the Moacir Andrade Museum collection, an institution's museum, where the teacher appears in a civic parade, on September 5,1974 , as a student of the institution. Starting from the autobi- 
ographical narrative, it is sought to reflect on the female presence in the ETFA and the considerations of the influences of the experiences in the self-training of the teacher.

Keywords: History of Women, Social Representations, Federal Technical School of Amazonas.

\section{RESUMEN PROFESOR, INGENIERO Y MUJER: EL SUJETO DE EXPERIENCIA EN EL PROCESO AUTOFORMADOR DE LOS PROFESORES}

Este artículo presenta la narración (auto)biográfica de un profesor del Instituto Federal de Educação, Ciência e Tecnologia do Amazonas - IFAM, y académico del Mestrado Profissional em Ensino Tecnológico - MPET, para problematizar las dimensiones formativas del autor en la mediación entre el alumno de los años 70 y el profesor de Dibujo Técnico. La idea para la investigación proviene de una fotografía del museu Moacir Andrade y Sala Memória, en la que el investigador / profesor aparece en un desfile cívico como estudiante. Basado en la investigación narrativa como metodología, se concluye que el método (auto)biográfico como procedimiento de análisis permite el auto entrenamiento a través del análisis de narrativas biográficas.

Palabras-clave: Investigación narrativa. (Auto)biografia. Formación docente.

\section{Introdução}

As mulheres nunca estiveram ausentes da história, embora a historiografia oficial as tenha esquecido. (TEDESCHI, 2012, p. 9)

As ideias iniciais deste artigo surgiram em uma visita ao museu Moacir Andrade e Sala Memória, do Instituto Federal de Educação, Ciência e Tecnologia do Amazonas (IFAM), Campus Manaus Centro (CMC), cadastrados no Instituto Brasileiro de Museus (Ibram), sob no no Sistema Nacional de Informações e Indicadores Culturais (SNIIC) ES-9337, quando uma fotografia trouxe inquietações sobre a condição da mulher/aluna da educação profissional dos anos 1970, ainda mais, por se tratar da própria pesquisadora, o que trouxe à tona memórias em silêncio. O Museu Moacir Andrade e Sala
Memória abrigam fotos, objetos, documentos oficiais e não oficiais, contando com um patrimônio material e imaterial da história da educação profissional do Amazonas e de uma instituição centenária.

A visita ao Museu Moacir Andrade e Sala Memória foi uma atividade de conclusão da disciplina eletiva Saberes e Experiências do Ensino Tecnológico no Amazonas, do Mestrado Profissional em Ensino Tecnológico (MPET), com o intuito de problematizar as representações sociais que o espaço da memória institucional apresentava. Ocorre que me deparei com um registro iconográfico que há muito chama minha atenção, uma fotografia, de 5 de setembro de 1974, na qual apareço em um 
desfile cívico, à Avenida Eduardo Ribeiro, em Manaus (AM), como parte do corpo discente da instituição, no início dos anos 1970.

Os diversos debates teórico-metodológicos da disciplina que acabara de concluir aguçaram ainda mais a necessidade em refletir a respeito daquele documento histórico, porém, naquele momento com algo a mais, a ideia clara da possibilidade de fazer uma reflexão à luz da subjetividade que uma imagem provocava. Assim, são as rememorações de uma ex-aluna e atual professora de Desenho Técnico e mestranda do MPET, que provocam a narrativa (auto)biográfica desta pesquisa, vislumbrando depreender o contexto de uma época por meio do olhar feminino que experienciou o pioneirismo das mulheres em uma escola técnica e o quanto essas experiências influenciaram em sua formação docente.

Na década de 1970, a Escola Técnica Federal foi de grande importância na formação de mão de obra para a Zona Franca de Manaus (AM), principalmente para o setor eletroeletrônico, bem como os cursos técnicos de Edificações e Estradas, por conta da expansão territorial defendida pelos governos militares. De todo o Brasil chegavam famílias em busca de emprego nas indústrias que se instalavam na cidade de Manaus e, é nesse contexto, que se registra a entrada da mulher nos cursos técnicos oferecidos pela Escola Técnica Federal do Amazonas (ETFA), mais precisamente em 1971, quando o Conselho de Professores aprovou, por unanimidade, o acesso de mulheres à ETFA (MELO, 2009).

A cidade de Manaus expandia-se. Novos bairros surgiam, as ocupações não planejadas passaram a ser uma realidade e a ETFA tornouse a referência para a equação educação pro-

1 Este estudo se posiciona em uma análise da sociedade perspectivada nos estudos de gênero, tendo como referência os escritos de Saffioti, Rago e Donna Haraway, em específico, o artigo “'Gênero' para um dicionário marxista: a política sexual de uma palavra", de Haraway, 2004. fissional = trabalho. Diante dessa figuração social que se desenhava, as relações de complementaridade entre expansão de Manaus nos moldes do capitalismo, educação profissional e Escola Técnica Federal revelavam, pois, as contradições socioculturais de uma sociedade étnica e culturalmente plural. Essa observação nos reporta aos escritos de Chartier, Escola, culturas e saberes, no qual a autora analisa a escola francesa e a brasileira para denotar as mudanças culturais que influenciavam a cultura escolar da sociedade moderna. Para Chartier (2005, p. 21), "Na sociedade de mercado, os saberes valem o que vale a posição social que eles permitem atingir". Na Manaus da década de 1970, estudar na ETFA era uma chance a mais de conseguir se inserir no mercado de trabalho, de alcançar o que Chartier (idem) chama de "posição social galgada pelos saberes escolares". o que se pergunta é: para todos e todas?

\section{A pesquisa (auto)biográfica: aproximações teóricas}

Ao olhar para uma fotografia ${ }^{2}$ que reflexões pode-se fazer de uma época? Pela fotografia, é possivel reconstruir aspectos que influenciaram a minha formação docente? Embasada nessas indagações fui levada a uma reflexão sobre o ser professora hoje e a relação com a presença feminina na ETFA da década de 1970.

A abordagem (auto)biográfica como território de formação e de aprendizagem apresenta uma história que se solidifica desde as últimas décadas do século XX. Um bom exemplo

2 A discussão sobre a utilização da fotografia pelas Ciências Sociais e Humanas é ampla e proficua, especificamente no que se refere às preocupações que o pesquisador deve estar atento para não banalizar uma imagem ou tratá-la como mera ilustração. Por ser um espaço reduzido para o debate a respeito dessa questão, quero manifestar que se levou em consideração dois textos para embasar minha leitura: "História das imagens", de Ivan Gaskell (1992) e "Autobiografia y autorretrato", de Luis Porter (2016). 
das reflexões desse campo de pesquisa são os encontros dos Congressos Internacionais sobre Pesquisa (auto)biográfica (CIPA), que tem ocorrido regularmente, desde 2004, e percorrido diversos estados como Rio Grande do Sul, Bahia, Rio Grande do Norte, São Paulo, Rio de Janeiro e Mato Grosso, abrangendo uma produção tanto institucional, quanto quantitativa e qualitativa de fôlego longo, evidenciando que a pesquisa (auto)biográfica não se concentra no eixo Sul/Sudeste, repercutindo uma representatividade regional.

Em diversas produções científicas que recorrem ao método (auto)biográfico, o que se destaca é a análise centrada na história de vida do pesquisador/pesquisado e sua relação com o processo formativo, problematizando as relações do processo de biografização e processos de formação e aprendizagem, para alcançar a consciência de si. o que faz um sujeito ser professor? Um professor tem sua prática baseada em sua experiência de vida? O que é ser professor? A prática do professor pode ser estudada nas relações desenvolvidas entre 0 cognitivo e o afetivo? Tais indagações dão uma mostra do campo de pesquisa que esse método possibilita ao trabalhar com as experiências de formação e de aprendizado numa perspectiva biográfica. 0 ser, constructo do cognitivo e do afetivo, se manifesta em sua história de vida, que, por sua vez, revela a experiência biográfica nas figurações construídas entre o eu e a escola, a família, a igreja, os amigos. Qual a importância dessas relações na formação do professor? Os trabalhos de Delory-Momberger (2011, p. 43) sobre pesquisa biográfica em educação mostram que,

A narrativa biográfica nessas sociedades [sociedades desenvolvidas] só pode ser a narrativa da identificação do indivíduo com as representações e os valores coletivos. E, tratando-se de narrativa de aprendizagem, será a narrativa da reprodução do mesmo e do processo de ade- quação do indivíduo aos modelos de savoir-faire ou de estado (de estabelecimento) que thes impõem seus pertencimentos. Nas estruturas relativamente fechadas e rígidas, que constituem as sociedades tradicionais, nas quais as funções sociais são, proporcionalmente, ainda pouco diferenciadas e identicamente transmitidas de geração em geração, os indivíduos não dispõem de um leque de possibilidades e de itinerários e, portanto, da margem de escolhas e de riscos, implicados na narrativa de formação.

Impor seus pertencimentos, identificar o indivíduo, seus valores e representações, são elementos constitutivos do método (auto)biográfico, uma vez que os acontecimentos que constroem uma história de vida são elementos de passagem para alcançar o significado das ações. Uma narrativa biográfica serve de substrato para se pensar as experienciações, as significações, as representações do indivíduo socialmente constituído, pois as tramas singulares dos indivíduos revelam as idiossincrasias de seu processo de formação com as forças sociais que the permeia.

Todo narrador, ao contar a sua história, organiza suas experiências e seus saberes dando forma a um movimento (auto)biográfico que ressignifica e dá sentido ao sujeito de carne e osso, em um jogo de relações entre o singular e o coletivo, sobressaindo uma percepção de ciência em que o sujeito cognoscente é o protagonista da investigação e o investigado. Ao levantarmos tais características, nota-se que o método (auto)biográfico coloca em xeque a certeza de um conhecimento científico baseado na linearidade temporal e na finalidade irreversivel da humanidade rumo ao progresso. Do mais, na interpretação de Souza (2010, p. 17), o método (auto)biográfico, que compõem as dimensões epistêmico-metodológicas da pesquisa narrativa, são prenhes de sentidos constituídos na superação do conceito de ciência em que separa o sujeito cognoscente do objeto pesquisado, senão vejamos: 
Já a autobiografia expressa o 'escrito da própria vida' [...], porque o sujeito desloca-se entre o papel de ator e de autor de suas próprias experiências, sem que haja uma mediação externa de outros. Dessa forma, entende-se que a abordagem biográfica e a autobiografia das trajetórias de escolarização e de formação, tomadas como narrativas de formação, inscrevem-se nesta abordagem epistemológica e metodológica por serem compreendidas como processo formativo e autoformativo por meio das experiências dos sujeitos em formação. Inserem-se também nessa abordagem porque ela constitui estratégia adequada e fértil para ampliar a compreensão do mundo escolar e de práticas culturais do cotidiano dos sujeitos em processo de formação.

Como se percebe, o método (auto)biográfico possibilita problematizar as dimensões formativas de professores na mediação entre o ser aluna e o ser professora e, nessa pesquisa, procurou-se indagar as relações que as experiências da aluna dos anos 1970 reverberaram na formação da professora de Desenho Técnico, do IFAM.

\section{Procedimento metodológico}

A proposição desta pesquisa foi discutir as dimensões formativas de uma professora à luz da experienciação que uma imagem iconográfica fez reacender. Para tanto, uma posição quanto ao caminho metodológico seguido deve ser apresentada, por se tratar de uma pesquisa narrativa que recorre ao método (auto)biográfico e a carta biográfica como instrumento de pesquisa. Sabe-se que a pesquisa narrativa apresenta uma arquitetura complexa, com diversas possibilidades teórico-metodológicas, além de inúmeros engates possíveis, tais como (auto)biografia e construção de si, entre outros. O recurso à história de vida para se pensar a formação e o aprendizado do ser professor apresenta aproximações teóricas entre experiências do ator/autor/sujeito, construção de sentidos e consciência de si, capitalizando a história de vida como uma construção narrativa que revela significados do ser. Nessa inferição epistemológica compactua-se o conceito de educação como uma prática social que dialoga com o eu singular e o eu social, se constituindo na "narratividade intersubjetiva". (SOUZA, 2010, p. 15) A utilização (auto)biográfica nos estudos sobre formação de professores recorre, assim, à narrativa de si por depreendê-la como processo autoformativo, por meio de ressignificações das experiências de seus narradores. Logo, a pesquisa narrativa coaduna com o método (auto)biográfico.

A pesquisa narrativa ${ }^{3}$ constitui-se de experiências de vida, de vivências, de práticas pessoais e sociais na intencionalidade de compreender as dimensões da vida narrada. Portanto, o método (auto)biográfico valora na narrativa a ênfase na rememoração da vida pessoal, colocando a subjetividade como elemento para se pensar a formação. Vale ressaltar, que o papel da memória, narrada na pesquisa narrativa, é fonte de análise acurada, é pedra angular nessa metodologia de pesquisa, por se constituir em artefato que poderá revelar como biograficamente o narrador organiza seus sentimentos, suas experiências, suas vivências, suas relações com o outro e com a sociedade, dando forma a sua identidade social.

Essa metodologia procura, portanto, decifrar o eu na sua singularidade, a partir do seu relato de vida, dos acontecimentos, da rede de práticas específicas, nas relações e tensões que o sujeito construiu para dar sentido ao mundo, à sociedade e, em específico, ao eu. Logo, este trabalho sustenta-se em Chartier (1991, p. 178), para quem percebe o texto como revelador de práticas sociais e posiciona-se “Contra uma definição puramente semântica

3 Sobre a denominação de pesquisa narrativa em educação, ver o texto "Viver, narrar e formar: diálogos sobre pesquisa narrativa", de Elizeu Clementino de Souza, 2018. 
do texto, é preciso considerar que as formas produzem sentidos, e que um texto estável na sua literalidade se investe de uma significação e de um estatuto inéditos [...]".

Note-se, que para Chartier (1991), a inteligibilidade da história está na representação dos diversos códigos simbólicos e materiais partilhados socialmente, os quais produzem significações diferenciadas, e, aqui, pode-se fazer uma justaposição para pensar a pesquisa narrativa que estuda o ser na sua singularidade e na sua materialidade histórica, ontológica e contingencial. Assim, não há um sujeito unitário-coletivo, como o construído na razão cartesiana, bem como, não há leitura neutra, posto que ela é uma prática de hábitos, de valores, de normas. Logo, para a pesquisa narrativa não há um sujeito unicamente cognoscente, pois ele é o resultado das relações de interdependência do eu com o outro desde o seu nascimento.

Souza e Meireles (2018, p. 19), ao refletir sobre os possiveis diálogos em pesquisa narrativa, faz uma colocação pertinente quanto ao olhar do pesquisador que pretende recorrer a esta metodologia,

Na pesquisa narrativa, cada sujeito, entendido como narrador, valendo-se dos próprios recursos biográficos, possui um motivo que organi$\mathrm{za}$, integra, direciona e elege os elementos e acontecimentos que dão forma a sua narrativa, tornando-a subjetivamente única, original e irrepetivel por conta dos significados pessoais contidos em cada uma das histórias narradas.

Nesse sentido, se a pesquisa narrativa visa, por meio da história de vida, a gerar fontes de pesquisa que suscitam a possibilidade de levantar as experiências do ator/autor/sujeito, suas relações sociais, suas construções sígnicas, suas subjetividades, acredito que um instrumento pertinente a essa metodologia é a carta biográfica. Esse instrumento de pesquisa foi utilizado por considerá-la um texto em que o autor poderá refletir sobre a sua produção ao escrevê-la e reescrevê-la, antes de enviar ao destinatário. Do mais, ao escrever uma carta, geralmente o remetente procura refazer uma frase, reescrever uma ideia, expressando seus sentimentos, seus valores, suas angústias e sua leitura de mundo.

\section{Carta ao professor: rememorações de uma aluna/ professora}

Prezado professor,

A atividade que fizemos em sua disciplina, quando da visita ao Museu Moacir Andrade e Sala Memória do IFAM, trouxe lembranças do meu tempo de aluna do curso de Edificações, na então ETFA. Ao deparar com uma fotografia na qual apareço em um desfile cívico, como aluna da instituição, no ano de 1974, várias lembranças e considerações se apresentaram e eu gostaria de compartilhá-las e, se possivel, trazê-las para uma discussão. Assim, passo a narrar as lembranças que trago daquele tempo.

O calor de setembro não chegava a ser desagradável na Avenida Eduardo Ribeiro, pois na década de 1970, as ruas do centro de Manaus ainda eram arborizadas e, naquelas manhãs, nosso maior desejo era que não chovesse, isso sim seria desagradável e todo o espetáculo preparado por meses não sairia como esperávamos. Vivíamos sob regime militar, mas em nossa adolescência nem ouvíamos sobre isso. Não era um assunto falado em nossos lares. Hoje, penso que talvez a distância e o isolamento do Amazonas do resto do país fizessem de nós um outro Brasil. Isso cooperava para a nossa adolescência alienada politicamente.

Em minha casa, por exemplo, havia sempre um exemplar do Pasquim e eu nem sabia que era uma revista de resistência. Lia por causa dos desenhos e porque também iria ler até 
se fosse bula de remédio. Um de meus tios comprava muitas revistas e através delas eu admirava a atriz Leila Diniz e sua irreverência. A música fazia parte do nosso cotidiano e era bem eclética, ouvíamos de Beatles a Luiz Gonzaga, de Elis Regina a Jackson Five. O Bem -amado, Selva de pedra e A escrava Isaura são as novelas de que me lembro e que fizeram sucesso à época. E, por causa de suas trilhas sonoras, conheci músicas de vários gêneros e esse hábito de ouvir música me acompanha sempre. Daí, a minha paixão pela banda marcial da ETFA e o meu interesse de saber mais sobre essa escola.

Em meados de 1973, avisei minha mãe que eu queria estudar o curso de Edificações, na Escola Técnica. Ela não gostou da ideia, questionou por que estudar em uma escola de homens? Falou que o minivestibular era dificil e por precaução foi fazer minha matrícula no curso de magistério, do Instituto de Educação do Amazonas, pois, segundo ela, eu seria uma ótima professora de crianças e, também, poderia não ser aprovada no minivestibular da ETFA. Na época, eu the dizia que não queria ficar até tarde da noite corrigindo cadernos e preparando aulas para ganhar um parco salário. Essa era a minha percepção do ser professora, profissão na qual a minha mãe era exemplo para outras professoras.

Minha mãe nasceu no interior do Amazonas e foi educada no Instituto Benjamim Constant, um internato de freiras que recebia, além das filhas da sociedade manauara, as bolsistas que vinham de famílias pobres, geralmente órfãs. Minha mãe perdeu os pais ainda na infância. No colégio interno, dedicou-se aos estudos, fez o magistério e depois lecionou por dois anos no interior para ganhar uma cadeira de professora na capital. Sendo a mais velha, conseguiu reunir seus cinco irmãos, que tinham sido espalhados em casa de parentes, após voltar para Manaus, já com a sua cadeira de professora do estado. Trabalhou como professora primária toda a sua vida, tornando-se uma excelente alfabetizadora e incutiu nos filhos o gosto pela leitura e pelos estudos.

Ela lia para nós todas as noites após o jantar e foi na enciclopédia $O$ tesouro da juventude que comecei a minha própria aventura através dos livros e onde nasceu meu amor pela poesia. Ela e meu pai também desenhavam. Meu pai desenhava os móveis que fazia e gostava de desenhar perfis de rostos. Foi observando e tentando imitar seus desenhos que me tornei desenhista e descobri o desenho arquitetônico na época do ginásio, quando surgiu meu interesse pela arquitetura.

Meu sonho era sair de Manaus para estudar Arquitetura e o curso de Edificações ajudaria muito na parte técnica e no aprendizado do desenho, que era a minha paixão. Eu mesma fiz minha inscrição para as provas de seleção da ETFA, mostrei o conteúdo que devia estudar para um de meus tios e ele emprestou os livros. Estudei e passei! O ano de 1974 era o quarto ano das mulheres na ETFA. Segundo conversas com a ex-diretora da instituição e também pesquisadora da história da ETFA, professora Maria Stela de Vasconcelos Nunes de Mello, em 5 de janeiro de 1971, o Conselho de Professores aprovou, por unanimidade, o documento de admissão de estudantes do sexo feminino e para atender às mulheres que chegavam, foi contratada uma orientadora educacional.

Hoje sabemos que o advento da Zona Franca de Manaus é que deu esse empurrão para as mulheres adentrarem nesse universo masculino da ETFA. As indústrias que chegavam à cidade necessitavam de mão de obra e as mulheres começaram a ocupar esse mercado aberto, principalmente nas fábricas de componentes eletrônicos. A Philco, por exemplo, era uma das indústrias que dava treinamento dentro da escola e contratava, principalmente, os alunos e alunas do curso de Eletrônica. 
O então diretor da escola, em 1974, que a dirigiu de 1972 a 1976, era o professor João de Pinho Pessoa Neto, um engenheiro que estava sempre construindo algo dentro dos muros do nosso quarteirão. Só sabíamos que ele era o diretor por causa das aulas de Educação Moral e Cívica, pois o professor dessa disciplina era um militar que nos ensinava toda a hierarquia no espaço da escola. Mas, quem mandava mesmo na gente era a orientadora educacional, a temida D. Leonilda. Ela nos mantinha na linha, ajudada pelo amado bedel "Seu" Osvaldo. Até se, por descuido, alguém pisasse a grama dos jardins, recebia o castigo de escrever plaquinhas com os dizeres "não pise na grama". Ajudei alguns a pintar as tais plaquinhas. Outra coisa proibida eram os namoros, nossos pais eram imediatamente chamados se ao menos nossa orientadora desconfiasse de algum envolvimento amoroso.

Os jogos estudantis eram de suma importância em nossas vidas e a ETFA era famosa pela quantidade de medalhas e de atletas que iam para as seleções estaduais para participar dos jogos nacionais. Tivemos inclusive um capitão da seleção brasileira de vôlei e a artilheira e artilheiro do handebol eram da minha turma. Isso para nós significava status dentro da escola. Também a ginástica rítmica era muito bem representada. Eu fazia um pouco de tudo, nos jogos internos jogava handebol e fazia corrida de obstáculos, mas era só para ficar o dia todo dentro da escola, nunca fui uma atleta de excelência. Porém, a veia de professora já se manifestava nas aulas de desenho que ministrava aos colegas que tinham dificuldades na disciplina. Embora gostasse desses momentos, não tinha a menor intenção de seguir a carreira de professora.

Nos jogos fora da escola e nos desfiles da semana da pátria, eram os momentos em que enfrentávamos os preconceitos de alguns. $\mathrm{Pa}$ lavras como "machudas" nós ouvíamos nesses eventos. Na verdade, eu considerava esses xingamentos como atitudes de ciúmes ou de raiva pelas nossas conquistas evidentes. Percebo, agora, que eu era ingênua e, com certeza, esses comentários entristeciam e afetavam minhas colegas homoafetivas. Jamais perguntei a elas a respeito do universo e das dificuldades que enfrentavam. Na minha percepção, éramos diferentes apenas na orientação sexual, provavelmente eu não percebia os preconceitos, naquele contexto pós anos 1960 e, também, pela educação recebida em casa. Meus pais não admitiam nem que me dirigisse a alguém como "aquela mulher" e sim "aquela senhora". 0 respeito para com o outro, fosse quem fosse, aprendi em casa com meus pais.

Nunca me senti diminuída ou rejeitada pelo fato de ser mulher dentro dos muros da ETFA. Conheci o preconceito de gênero quando cursava a faculdade de Engenharia e fui rejeitada para um emprego por ser do sexo feminino e isso me foi dito com todas as letras. Outro fato interessante daquela época era a diversidade de posições sociais dos alunos. Meu pai era marceneiro e trabalhava em um estaleiro. A filha do dono do estaleiro era minha colega de turma. Os filhos da elite manauara também procuravam os cursos técnicos da ETFA porque queriam fazer as faculdades de Engenharia. Manaus era uma "ilha" e as escolas públicas eram consideradas de qualidade. As escolas privadas que existiam eram escolas religiosas - Salesianas ou Batistas.

O mundo do trabalho começou para mim quando eu tinha 12 anos. Sendo a mais velha de oito irmãos, percebi a dificuldade financeira de meus pais e resolvi ganhar dinheiro costurando, cortando cabelo, fazendo bijuterias e serviços de office boy (existe o termo office girl?) para meus tios. Não existia a internet e os serviços de depositar ou descontar cheques, entregar documentos e fazer pagamentos eram tarefas dos office boys. Fiz um curso de cabeleireira, 
aprendi a costurar com uma de minhas tias e as "bijus" eu aprendi olhando o trabalho artesanal dos muitos hippies que frequentavam as praças da cidade. Na escola, juntei-me a outras garotas que também costuravam, faziam bijuterias e então vendíamos nossas bolsas, blusinhas e pulseiras para as colegas.

Em minha família, todas as mulheres trabaIhavam. Minha mãe sempre dizia que só podíamos casar depois de ter uma profissão. Só agora tenho a consciência e uma percepção mais ampla do valor da educação dessa mulher na minha vida. Ouvi dizer que nossa ascendência indígena é que nunca nos permitiu pensar que mulher foi feita pra casar, cuidar do marido, da casa e dos filhos, isso a gente só descobriu depois, olhando para a história das sociedades, conhecendo as vidas de mulheres de outros contextos sociais. Quando saí de Manaus, aos 23 anos, o Sudeste e o Sul do Brasil me mostraram vários outros preconceitos, entre eles os de raça e gênero.

Não estou afirmando que não existiam preconceitos em Manaus ou no Amazonas, só que eram invisiveis no meu "mundinho". Foi saindo dele que me dei conta da minha bisavó negra casada com um português do olho azul e que me deram um avô sarará (é como chamavam os afrodescendentes de cabelo loiro e olhos azuis); da minha avó materna índia e avó paterna judia, casada com meu avô cearense. Meu pai contava que seus pais haviam fugido para Manaus para casarem. Mas, atualmente, não tenho mais como saber a razão, provavelmente uma bela história de amor envolvendo preconceitos. Fica a imaginação desse romance sem registro.

A minha nota de entrada na ETFA derrubou o preconceito de minha mãe em relação à "escola de homens" e ela passou a apreciar as minhas conquistas na escola. Quando passei no concurso da prefeitura para o cargo de desenhista técnica e no vestibular para uma enge- nharia, ela entendeu e apoiou todos os meus planos e voos. Pena que não estava mais neste mundo quando me tornei professora, profissão que ela sempre teve certeza que eu havia nascido para exercer.

Ao terminar o curso de Edificações, eu ainda não tinha condições de mudar de cidade para estudar a sonhada Arquitetura, então, fiz o vestibular para Engenharia Operacional da Indústria da Madeira, um curso noturno da Universidade de Tecnologia da Amazônia (UTAM), atual Universidade do Estado do Amazonas (UEA), e quando terminei a Engenharia fui para Curitiba, onde fiz licenciatura em Desenho, na Escola de Música e Belas Artes do Paraná (Embap).

Minha vida profissional docente começou por acaso, depois de terminar minha segunda graduação na cidade de Curitiba e retornar para Manaus, em 1991. Comecei a lecionar em 1991 na Universidade Federal do Amazonas (UFAM), como professora substituta de Desenho Técnico. Era para ser temporário, apenas enquanto a professora da disciplina estava de licença maternidade. Mas, encontrei minha realização profissional ensinando o que eu mais sabia fazer: desenhar! Em 1992, passei na seleção para professor substituto na então Escola Técnica Federal do Amazonas (ETFAM), atual IFAM, e no ano seguinte, no concurso para professora efetiva. 0 fato de ser professora da minha querida escola me fez buscar os espelhos dos professores que admirava, queria ser como eles.

Voltando àquela manhã de setembro de 1974: o dia 5 era o Dia do Amazonas. Dia em que o Amazonas foi elevado à categoria de Província. Cada ano, a Secretaria de Educação escolhia um tema para ser desenvolvido na avenida pelas escolas. No ano de 1974, o tema era os estados brasileiros, e a nós, coube representarmos o estado de Santa Catarina. Foi uma festa, levamos bicicletas, carroças com 
flores e as poucas garotas loiras para representar as cidades daquele estado. Mas, o grande referencial da escola naquela época era a sua banda marcial. Não era uma simples fanfarra. Havia uma concorrência com as bandas marciais do Colégio Estadual D. Pedro II e do Colégio Benjamin Constant.

A ETFA era, para os jovens daquela década, a certeza de um emprego após a conclusão do ensino médio com uma formação técnica. Os cursos eram de quatro anos para quem queria o diploma de técnico, e de três para quem desejasse o certificado do ensino médio, o então segundo grau. A escola era vista com muito apreço pela sociedade amazonense, não só pela educação de qualidade, mas também no esporte e eventos culturais. A importância dada ao folclore e aos esportes contagiava todas as escolas da cidade, inclusive as privadas, que eram, na sua maioria, escolas católicas dirigidas por freiras e padres.

Com o advento da Zona Franca de Manaus, que gerou carência de mão de obra especializada para as indústrias que se estabeleciam na cidade, as mulheres foram inseridas nesse mercado de trabalho, e a ETFA formava boa parte dessa mão de obra, através de seus cursos de Eletrônica e Telecomunicações, Mecânica, Edificações, Química e Estradas.

Nos quatro anos em que cursei Edificações, vi poucas mulheres escolherem os cursos de Mecânica e de Estradas, a presença feminina era maior em Edificações e Eletrônica e Telecomunicações, pois esses eram os mercados de trabalho que absorviam a mão de obra feminina. Percebo aqui, que alguns mercados de trabalho ainda tinham seus preconceitos. E também a "permissão" para elas em alguns campos de trabalho vem da necessidade de mão de obra e não tanto provocada por uma luta de inserção.

Nos desfiles cívicos de 5 de setembro, as atletas formavam o primeiro pelotão das alu- nas e algumas eram especialmente escolhidas como porta bandeiras e para desfilar à frente da banda marcial. Os professores de educação física é que faziam essa escolha e o critério era a beleza e o porte atlético das meninas. Concursos de beleza sempre perseguindo a vida da mulher, e a beleza a partir de algum olhar (só uma provocação). A marcha era com os punhos cerrados, não sei a razão, pois só a ETFA desfilava assim.

Figura 1 - Desfile de 5 de setembro de 1974

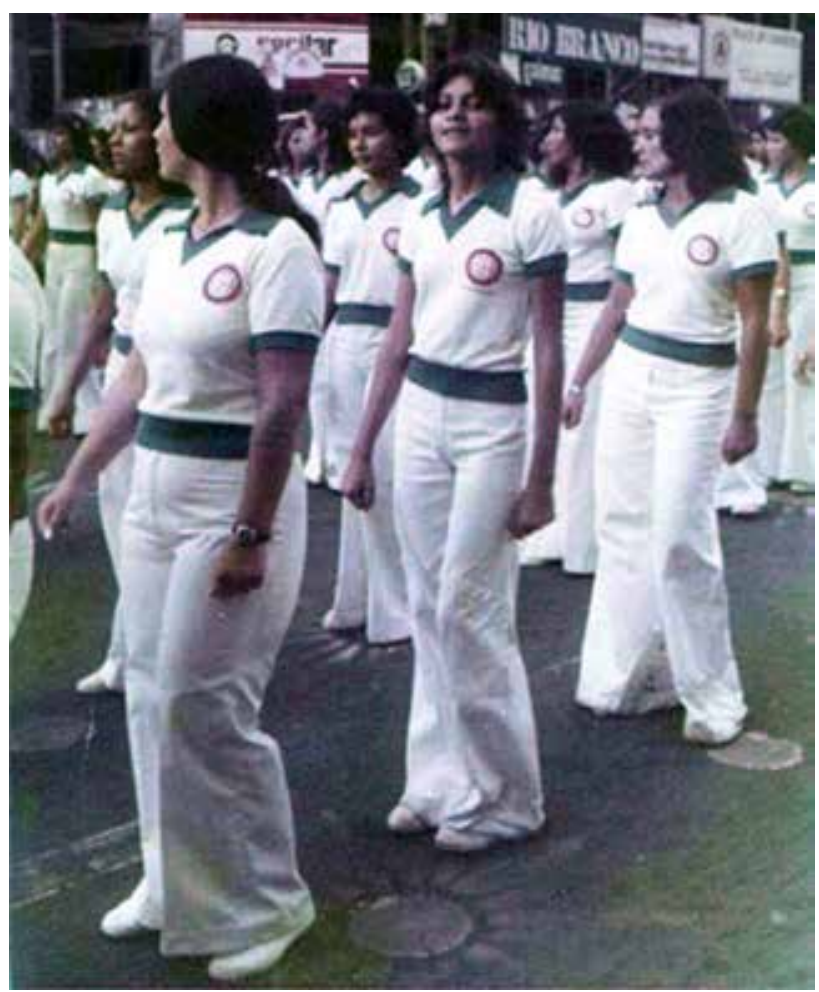

Fonte: Museu Moacir Andrade e Sala Memória (IFAM/ CMC).

Quanto às mulheres que foram minhas professoras na época de estudante da ETFA, lembro a professora Dalva, de Biologia, Francisca e Thalita, de Português, Nazaré, de História, e Jucineide, das disciplinas técnicas. Mulheres fantásticas que me inspiraram quanto ao tipo de professora que tento ser. Quando fui admitida como professora, em 1992, a professora Dalva ainda trabalhava e eu conversava bastante com ela na sala dos professores. Ela tinha um especial orgulho de suas ex-alunas que agora 
eram professoras da instituição, sendo a maioria de nós da área de exatas. A professora Jucineide era engenheira civil e muito admirada por sua elegância e sua inteligência.

Minha mãe e minhas professoras serviram de espelho na minha autoformação docente. 0 desejo de ser como elas, mulheres que contribuíram positivamente para a formação de outros com seus conhecimentos, atitudes e coragem, acompanha até hoje minha vida profissional docente. Embora na adolescência eu não tivesse a percepção da luta feminina, hoje, essa posição eu assumo também como educadora, e trago sempre para minha autoformação o aprendizado, as conquistas e as inúmeras lutas dessas mulheres.

Um fato que marcou profundamente a minha caminhada docente no IFAM foi a atitude do meu professor de Desenho Básico, na ETFA, professor Manuel Rodrigues. Quando soube que eu era professora de Desenho Técnico, ele veio até a escola e me presenteou com os seus instrumentos de desenho. Foi um momento de grande emoção! Vejo a minha construção docente baseada no espelhamento dos professores que me inspiraram em toda a caminhada de estudante.

Ao ser aprovada como professora de Desenho Técnico Arquitetônico na então ETFAM (a sigla havia ganhado o " $M$ " no final), depois de ter cursado duas graduações e ter passado pela experiência da docência na UFAM, no departamento de Design, fui levada a lembrar dos quatro anos da minha formação técnica e de como aprendi com meus professores daquela época. 0 desenho havia me dado todos os empregos, na Prefeitura de Manaus, no Instituto de Terras do Amazonas e no Banco Bamerindus do Brasil, em Curitiba. Agora, enquanto professora, iria ensinar o que sabia e buscar atualizações para que meus alunos também pudessem ser bons técnicos e entrar no mercado de trabalho sem dificuldades.
O fato de ter sido aluna do curso de Edificações facilitou entender o que aqueles adolescentes precisavam saber da minha disciplina, para que ao final estivessem aptos na profissão que escolheram. Busquei a lembrança dos meus professores de desenho e de todos os outros a quem admirei enquanto aluna. Entendi, ainda na UFAM, que eu precisava descobrir como o aluno aprende, como fazê-lo usar suas habilidades na execução de um bom projeto arquitetônico utilizando os instrumentos, equipamentos e ferramentas destinadas a isso.

Os desafios maiores surgiram quando tive que trabalhar com outros cursos. Alunos de Edificações geralmente escolhem esse curso porque gostam de desenho, mas os outros técnicos que precisam ter conhecimento de leitura e interpretação de desenho, como os dos cursos de Mecânica, Eletrotécnica e Química, o professor precisa antes eliminar o medo da disciplina, fazê-los entender que são capazes e desmistificar um sentimento de que precisam ter "dom" para o desenho. Pois Desenho Técnico é matemática.

O início da minha carreira profissional docente foi marcado pelo espelhamento da prática docente de meus professores e de minha mãe. A paixão dos meus professores pelo aprendizado do aluno e a lembrança de como minha mãe amava seus pequenos, sabia seus nomes, conhecia os pais, tratava-os como pessoas e por isso eles a amavam. Acredito que minha mãe professora é meu maior espelho e se conseguir ser a metade do que ela foi, saberei que fiz a coisa certa. Dona Terezinha sabia ensinar e eu tento saber também.

Prezado professor, finalizo esta carta agradecendo pelo aprendizado e por ter permitido esse momento de reflexão dos processos formadores da minha vida profissional docente. Com muito apreço, 


\section{O sujeito da experiência na}

\section{reflexividade da escrita de si}

A pesquisa narrativa, como já mencionado, permite ultrapassar uma visão de pesquisa científica que separa, como se fossem dois campos distintos, o pesquisador e o objeto. Essa metodologia estabelece uma maneira de como refletir o eu na interface entre pesquisador e pesquisado. Partindo dessa premissa, acredito ser um corpus documental revelador da relação auto/hétero a carta biográfica enviada ao professor da disciplina Saberes e Experiências do Ensino Tecnológico no Amazonas, do curso do MPET e fonte desta pesquisa, ao perceber em sua narrativa fragmentos da minha história de vida e no meu fazer educação, na condição de mulher/professora.

Essa relação multidimensional torna-se reveladora de relações de poder desiguais estabelecidas socialmente, para a manutenção de uma cultura de privilégios, geralmente falocêntrica, centrada na valorização de um modelo preestabelecido culturalmente como o padrão masculino a ser seguido. Essa observação só se tornou possivel, aqui, na reflexão proposta pelo método (auto)biográfico e na percepção de ciências humanas como uma construção do conhecimento embasado na experiência vivida pelo sujeito. A obra Sobre a ciência da incerteza, do sociólogo Franco Ferrarotti (2015), é um bom exemplo de como analisar as relações manifestas simbolicamente na sociedade. 0 autor argumenta, com um texto bem estruturado teoricamente, que as ciências sociais e humanas foram motivadas, durante séculos, a desenvolver suas investigações a partir de método quantitativo, sustentando o conhecimento científico em procedimentos rigorosos de cálculos de medição matemática. Contudo, argumenta Ferrarotti (2015), que conflitos sociais de determinada natureza somente serão compreendidos pelo viés da abordagem quali- tativa e pelo entendimento de que a sociedade não se deixa ler na medição matemática.

A abordagem de Ferrarotti centra-se na perspectiva (auto)biográfica, valorizando o sujeito enquanto dotado de relativa autonomia em determinado tempo histórico. Observa o sociólogo que "A partir da década de 1950, estava em curso uma nova orientação baseada numa análise crítica da relação entre 'fatos' e 'valores' [...]" (FERRAROTTI, 2015, p. 12). Essa observação visa sustentar que o fato só existe a partir dos enunciados que the dão significado, pois não despreza a dimensão histórica e, portanto, quando se considera que o fato apresenta uma distinção lógica dos valores que aquele produz, está se trabalhando com um conceito de ciência imutável e a-histórico, considerando-a como um processo de abstração da realidade em que a "ideia" a suplanta e a explica. Ao observar a pesquisa sociológica, Ferrarotti (2015, p. 16) sugere que o sociólogo deverá ir além da perspectiva da lógica matemática,

Acresce-se que, para lá da suposta inequivocidade da razão, o sociólogo deve dar atenção ao raciocínio que figura nos gestos, nas expressões faciais e nas inflexões discursivas, ou seja, toda a subcorrente que corresponde ao modelo soft da experiência, a substância que não consegue sobreviver e, por definição, entrar na lógica cartesiana de escrita.

Assim, Ferrarotti chama para o debate a necessidade de pensar a relação entre teoria e sociedade, superando a perspectiva abstracionista, ao trazer para a observação o imponderável das relações sociais que escapam da observação cartesiana, quais sejam, a subjetividade, a narrativa, as relações dos indivíduos na sua cotidianidade, as construções ordinárias de condutas, normas e padrões, uma vez que é no fazer-se enquanto sujeito que se legitima o social, bem como são nas relações sociais que se (re)conhece um ser humano. 
Uma pessoa nunca é um indivíduo. Seria mais adequado denominá-la de universo singular. Ela encontra-se, simultaneamente, 'totalizada' e universalizada pela sua época, retotalizando -a ao reproduzir-se nela como singularidade. Apresenta-se como universal, através da universalidade singular da história humana, e singular, através da singularidade universalizante dos seus projectos, exigindo, por isso, que o seu estudo seja efectuado em ambos os sentidos. (FERRAROTTI, 2015, p. 65)

Tais observações me levou a perceber que os fatos registrados na fotografia e na carta biográfica dizem pouco se não forem lidos por meio de seus valores sígnicos. E, é nessa reflexão que as narrativas imagética e escrita ganharam outra dimensão neste trabalho, revelando a complexidade de uma sociedade constituída por três elementos: capitalismo, patriarcalismo e racismo. Percebe-se, a partir desse olhar, que o eu mulher/professora se formou em um contexto marcado pela presença da cultura masculina, que determinava o lugar da mulher e do indígena na sociedade. 0 que instigou a partir dessa constatação foi: como identificar que tempo era esse? Era o tempo em que imperava a igualdade de condições?

Em diversas passagens da carta biográfica, verifica-se o papel social da mulher da década de 1970 em Manaus. Vejamos alguns indícios: a família se posicionando contrária à formação profissional da filha por ser uma "profissão masculina"; a escola exercendo uma disciplina rigorosa em que o peso maior era o comportamento feminino em relação não à aprendizagem, mas ao corpo; o "cuidado" em reprimir o comportamento da aluna em relação ao aluno - namorar, em nenhuma hipótese era permitido às alunas -; a mulher representada pela beleza física - as mais bonitas estavam à frente, poderiam aparecer e a estas cabiam conduzir os símbolos da nação em desfiles cívicos, estarem à frente da banda da escola etc. Cabe lem- brar, ainda, que eram escolhidas pelos professores de Educação Física, ou seja, era papel do homem/professor escolher as alunas que se destacavam.

Atualmente, pergunto-me quais eram as normas estabelecidas pela ideologia dominante, nos anos 1970, sobre família, escola e beleza? Quais valores de família que se apresentavam e o que isso significava para a mulher? Quais conceitos (ou preconceitos) esses professores utilizavam para escolher as mais bonitas? Nunca ficou claro, ou melhor, não ficava, porque se analisar esses acontecimentos para além da lógica racional/cartesiana, podese identificar naquela sociedade o que Saffioti (1987) chama de "naturalização do processo social".

Para Saffioti, a naturalização do processo social é delimitada pelas contradições que ela apresenta em seu bojo. A autora pergunta por que é natural ao homem o papel de mantenedor da família, se em muitas famílias as muIheres exercem dupla, tripla função em relação ao trabalho. Por que cabe ao homem ser livre para viver o espaço público, enquanto que à mulher reserva-se o ambiente doméstico para exercer a sua sociabilidade? Por que as regras, para o homem, em relação à conduta sexual, em específico para o heterossexual, são frouxas socialmente, enquanto para a mulher são extremamente rígidas? A resposta da pesquisadora está perspectivada na dimensão sociocultural, a qual permite realizar outra leitura do real, desvelando as relações de poder incrustada nos papéis que homens e mulheres exercem na sociedade. Para além das funções biológicas, as relações humanas produzem relações de poder que determinam as figurações sociais que revelam as hierarquias entre homens, mulheres, crianças, velhos, gays, pretos, brancos etc.

Em uma passagem da sua obra, Saffioti (1987, p.97) nos lembra que: "São tantas as 
possibilidades de redefinição das relações humanas, que nada impede que se tente eliminar a assimetria, a desigualdade, visando a um maior bem-estar das pessoas enquanto seres humanos, plenos de potencialidades". As observações de Saffioti coadunam-se com as indagações apresentadas neste texto, uma delas é a compreensão de ser professora, numa perspectiva sociocultural, por meio da experiência de uma mulher manauara da segunda metade do século XX. Para tanto, procurou-se reconduzir seu olhar de pesquisadora para 0 alargamento da complexidade das relações sociais, bem como trabalhar na abordagem da experiência vivida na contingência histórica e no método interpretativo. Daí, a necessidade de buscar o sentido construído historicamente pela mulher/engenheira/professora em uma sociedade que valoriza o culto ao fálico.

As sociedades têm seus estereótipos rigidamente constituídos e representam o papel de cada membro no corpo social. 0 homem e a mulher, conforme a sociedade, têm seus papéis sociais simbolicamente determinados e essas construções simbólicas são precedidas de poder, ou melhor, de relações de poder. Posto que não é um fato dado, uma força material a ser desmembrada do tecido social, mas, é sempre relacional. É uma dinâmica construída nas práticas sociais de indivíduos interdependentes. Quanto mais complexa uma sociedade, mais complexas são as teias de construção das relações de poder, portanto, não há sociedade que abdique das relações de poder para se constituir, pois são nessas relações que se estabelecem hierarquicamente os papéis sociais dos seus membros. Essa perspectiva chamanos para pensar as relações de poder como algo que vai além da força institucional, ou seja, o poder, enquanto relação, não está em uma instituição, no Estado por exemplo, mas, no conhecimento, na política, na família, na igreja, na escola, no sexo, na ciência etc.
Rago (1985) escreve um texto discutindo como a ciência do final do século XIX constrói uma representação do feminino ao abordar o papel da prostituta na sociedade carioca, visando demonstrar como as relações de poder, nesse caso o da ciência, estabelece estereótipos sociais. Ao discutir a prostituição, notase que a construção sociocultural da mulher da sociedade burguesa foi tecida, também, pela ciência, observa Rago. Partindo da figura maculada de mulher, aquela que entre outros comportamentos ousa viver sua sexualidade e externar publicamente com seu comportamento "atípico" (mulher pública), Rago (1985, p.223) identifica, na narrativa científica do doutor $F$. Ferraz de Macedo, a representação da mulher honesta, demonstrando como o discurso científico naturaliza o papel da mulher na sociedade brasileira do final do século XIX e início do século XX.

O contraponto dessa figura maculada, por sua vez, reforça a possibilidade de valorização, de promoção e de imposição de um novo modelo de feminilidade: a mulher esposa-dona-de-casa-mãe-de-família, vigilante, ordeira, higiênica, responsável pelos membros da família, porém, dessexualizada: a 'rainha do lar'.

Essa construção do feminino na sociedade burguesa brasileira não ocorre por mero prazer despretensioso do mundo masculino. Essa definição social de mulher está alicerçada na construção de um estereótipo que garantirá uma relação de poder assimétrica entre homens e mulheres, em um tempo de mudança que a sociedade brasileira vivenciava. Pode-se redefinir, diz Rago (1985, p. 228), as relações intrafamiliares, mas o poder do homem sobre a mulher estaria mantido.

A valorização do papel da mãe e de um novo ideal de feminilidade, difundido pela sociedade burguesa desde meados do século XIX e, nos meios operários, nos inícios do século no Brasil, tem o objetivo de convencer as mulheres 
de que elas amam naturalmente seus filhos, de que nasceram para procriar, de que o amor materno é uma vocação inata, pura e sagrada, e de que seu espaço natural resume-se ao lar. Tudo o mais inscreve-se no campo da anormalidade e recebe o estigma da culpabilidade. Entre a Santa Maria e a Eva, a mulher não teve nenhum espaço permitido.

Assim, Rago procura analisar como a ciência construiu uma representação do feminino para a sociedade carioca do final do século XIX, demonstrando que a fonte de poder na sociedade está nas relações desenvolvidas em suas diversas dimensões sociais, nesse caso, no conhecimento científico.

Retomando a carta biográfica enquanto objeto de análise para pensar a minha condição de mulher/professora, evidencia-se que as relações de poder se manifestavam de forma latente no estereótipo do feminino dos anos 1970 na ETFA. Contudo, com uma margem maior de movimento da mulher que nos anos iniciais do século XX. Esse afrouxamento do padrão que determinava o papel social da mulher pode ser verificado em diversos excertos da carta. Havia mulheres nos anos 1970 que "ousavam" dizer seu nome, como Leila Diniz. A família rezava, acima de tudo, pelo comportamento da mulher casta, mas o trabalho estava na ordem do dia, lembrava a mãe. Fazer a inscrição para o processo seletivo, estudar em um curso "masculino", aprender desenho com o homem da casa, ter amigas de outra orientação sexual, vejo, hoje, como indícios de maior liberdade de movimentação da mulher e que me faz ser a mulher/professora que sou.

Além disso, aqueles movimentos imperceptíveis são sintomas de uma sociedade em que o antigo e o novo estavam presentes, em disputa, redefinindo as relações de poder e, por conseguinte, construindo outras figurações sociais. Contudo, há que se registrar que tais figurações sociais reverberam mais na singularidade dos seus membros, do que na rede- finição dos papéis no todo social, ou seja, a Inalda pode ser professora de Desenho Técnico, engenheira, mulher emancipada profissionalmente, mas, a condição de ser mulher na sociedade manauara ainda se baliza pelo estereótipo forjado pelo barro da cultura falocêntrica, respaldada na fonte de poder econômico do capitalismo, na fonte de poder social do patriarcado e na fonte de poder do discurso racial preconceituoso.

Assim, a mulher/professora vai se construindo e se reconstruindo ao fazer-se ser, numa perspectiva relacional entre o mundo do trabalho, a política nacional, a família, a escola, a universidade, os amigos e amigas e o ser. Posso argumentar, ainda, que é nesse jogo de relações que a minha singularidade se revela. A minha posição enquanto mulher, professora e engenheira se manifesta nas subjetividades transformadas em experiência, ao dar sentido à minha existencialidade.

Uma observação deve ser feita, a de que um indivíduo, para se relacionar, apropria-se de um padrão de conduta já estabelecido como norma social. E, nesse processo, desenvolve um controle de si, tais como as manifestações de constrangimento e vergonha, demonstrando que a consciência-nós interfere, assim, no processo de formação da consciência-eu. Contudo, não anula e não apaga as manifestações de si enquanto sujeito ontológico, que constrói a inteligibilidade da vida na forma e nos sentidos que vão se revelando, na estruturação da narrativa, as disposições entre o eu e o outro.

$\mathrm{Na}$ carta biográfica verifico que os acontecimentos, os conflitos, os anseios registram uma busca de si. Essas reflexões remetem aos escritos de Delory-Momberger (2015, p. 36), quando essa apresenta em seus escritos um modelo de narrativa que recorre às origens históricas e antropológicas para pensarmos as nossas representações e práticas biográficas, argumentando que, "fazer a narrativa de vida 
consiste em retraçar as etapas de uma gênese, o movimento de uma formação em ação, em outras palavras, contar como um ser se tornou o que ele é." (Grifo nosso).

\section{Considerações finais}

As narrativas (auto)biográficas têm sido amplamente utilizadas nas pesquisas em educação e formação de professores. Através deste relato de minha própria experiência, posso perceber a força de um movimento reflexivo através da narrativa, que auxilia no meu processo de autoformação docente e ajuda a compreender minha própria trajetória. Dessa maneira, a minha história no IFAM possui um sentido que está representado nas narrativas imagéticas do museu da instituição, na carta biográfica, isto é, em fragmentos de memórias que são capazes de construir um sentido que tenho dado ao meu viver.

A presença da mulher na professora, a engenheira na mulher e da professora na engenheira é marcante e se materializa simbolicamente na figura de minha mãe, das professoras, colegas de escola, das alunas, e, também, nos estereótipos carregados de preconceitos e de relações de poder desiguais, pois a força para lutar nesse contexto desigual fez com que eu me posicionasse enquanto mulher na sociedade manauara. Acredito que foi a necessidade de lutar contra uma ordem desigual estabelecida naquela sociedade dos anos 1970 que me alimentou, energizou, para as minhas conquistas e para os meus projetos pessoais.

Finalizo, sustentando que a minha pesquisa de mestrado trabalha com narrativas de professores bacharéis, no intuito de compreender a constituição docente desses professores que não passaram por uma licenciatura. $E$, no meio do caminho, deparei com a minha condição, isto é, descobri que estava estudando um pouco de mim no outro.

\section{Referências}

CHARTIER, Anne Marie. Escola, culturas e saberes. In: XAVIER, Libânia Nacif; CARVALHO, Marta Maria Chagas de; MENDONÇA, Ana Valeska; CUNHA, Jorge luiz da. (Org.). Escola, culturas e saberes. Rio de Janeiro: FGV, 2005. p. 9-28.

CHARTIER, Roger. O mundo como representação. Revista Estudos avançados. São Paulo, v. 5, n. 11, p. 173-191, 1991. Disponível em: https://www.scielo.br/ pdf/ea/v5n11/v5n11a10.pdf. Acesso em: 25 jan. 2020.

DELORY-MOMBERGER, Christine. Narrativa de vida: origens religiosas, históricas e antropológicas. Revista Educação em Questão, v. 40, n. 26, p.31-47, jan./ jun. 2011. Disponível em: https:/ / periodicos.ufrn.br/ educacaoemquestao/article/view/4039/3306. Acesso em: 28 nov. 2019.

DELORY-MOMBERGER, Christine. Narrativa de investigação profissional: um dispositivo de pesquisaformação sob a forma de uma escrita implicada. In: SOUZA, Elizeu Clementino de. (Org.). (Auto)biografias e documentação narrativa: redes de pesquisa e formação. Salvador: EDUFBA, 2015. p. 161-172.

FERRAROTTI, Franco. Sobre a ciência da incerteza: o método biográfico na investigação em ciências sociais. Mangualde: Edições Pedago, 2015.

GASKELL, Ivan. História das imagens. In: BURKE, Peter. (Org.) A escrita da história: novas perspectivas. São Paulo: Ed. UNESP, 1992. p. 237-272.

HARAWAY, Donna. Gênero para um dicionário marxista: a política sexual de uma palavra. Cadernos Pagu, n. 22, p. 201-246, 2004. Disponivel em: https:/ / www.scielo.br/pdf/cpa/n22/n22a09.pdf. Acesso em: 25 jan. 2020.

MELO, Maria Stela Vasconcelos Nunes. De Escola de Aprendizes Artífices a Instituto Federal de Educação, Ciência e Tecnologia do Amazonas: cem anos de história. Manaus: Editora, 2009.

PORTER, Luis. Autobiografia y autorretrato. Revista Brasileira de Pesquisa (Auto)biográfica, v. 1, n. 3, p. 402-414, set./dez. 2016. Disponivel em: https:// www.revistas.uneb.br/index.php/rbpab/article/ view/2993/1932. Acesso em: 25 jan. 2020. 
RAGO, Luiza Margareth. De Eva a Santa, a dessexualização da mulher no Brasil. In: RIBEIRO, Renato Janine. (Org.). Recordar Foucault. São Paulo: Brasiliense, 1985. p. 219-228.

SAFFIOTI, Heleieth Iara Bongiovani. 0 poder do macho. São Paulo: Moderna, 1987.

SOUZA, Elizeu Clementino de. Pesquisa narrativa, (auto)biografias e história oral: ensino, pesquisa e formação em Educação Matemática. Ciências Humanas e Sociais em revista, v. 32, n. 2, p. 13-27, jul./ dez. 2010. Disponível em: https://ufrrj.br/seer/index.php?journal=chsr\&page=article\&op=view\&path[]=809. Acesso em: 13 fev. 2020.

SOUZA, Elizeu Clementino de. (Org.) Autobiografias, histórias de vida e formação: pesquisa e ensino.
Porto Alegre: EDPUCRS; Salvador: EDUNEB, 2013.

SOUZA, Elizeu Clementino de; MEIRELES, Mariana Martins de. Viver, narrar e formar: diálogos sobre pesquisa narrativa. In: NAKAYAMA, Bárbara Cristina Moreira Sicardi; PASSOS, Laurizete Ferraguti. (Org.). Narrativas, pesquisa e formação de professores: dimensões epistemológicas, metodológicas e práticas. Curitiba: CRV, 2018. p. 17-38.

TEDESCHI, Losandro Antonio. As mulheres e a história: uma introdução teórico metodológica. Dourados: Ed. UFGD, 2012.

Inalda Tereza Sales de Lima é acadêmica do Mestrado Profissional em Ensino Tecnológico (MPET) do Programa de Pós-Graduação em Ensino Tecnológico (PPGET) do Instituto Federal de Educação, Ciência e Tecnologia do Amazonas (IFAM). Professora do Ensino Básico, Técnico e Tecnológico do IFAM. Bacharel em Engenharia Operacional da Indústria da Madeira pela Universidade de Tecnologia da Amazônia (UTAM) e licenciada em Desenho pela Escola de Música e Belas Artes do Paraná (Embap). É membro do grupo de estudo e pesquisa sobre Processos Formativos de Professores no Ensino Tecnológico, vinculado ao Conselho Nacional de Desenvolvimento Científico e Tecnológico (CNPq). E-mail: inalda.lima@ifam.edu.br

Nilton Paulo Ponciano é doutor em História pela Universidade Estadual Paulista Júlio de Mesquita Filho (Unesp). Professor do Ensino Básico, Técnico e Tecnológico do Instituto Federal de Educação, Ciência e Tecnologia do Amazonas (IFAM). Professor do Mestrado Profissional em Ensino Tecnológico (MPET) do Programa de Pós-Graduação em Ensino Tecnológico (PPGET) do IFAM, Campus Manaus Centro (CMC). É membro do grupo de estudo e pesquisa sobre Processos Formativos de Professores no Ensino Tecnológico, vinculado ao Conselho Nacional de Desenvolvimento Científico e Tecnológico (CNPq).E-mail: nilton.ponciano@ifam.edu.br 